\title{
MULTI-CRITERIA COMPARATIVE ANALYSIS OF THE USE OF SUBTRACTIVE AND ADDITIVE TECHNOLOGIES IN THE MANUFACTURING OF OFFSHORE MACHINERY COMPONENTS
}

\author{
Mariusz Deja \\ Mieczysław Stanisław Siemiątkowski \\ Dawid Zieliński \\ Gdańsk University of Technology \\ Faculty of Mechanical Engineering, Department of Manufacturing and Production Engineering, Poland
}

\begin{abstract}
The dynamic development of additive manufacturing technologies, especially over the last few years, has increased the range of possible industrial applications of $3 D$ printed elements. This is a consequence of the distinct advantages of additive techniques, which include the possibility of improving the mechanical strength of products and shortening lead times. Offshore industry is one of these promising areas for the application of additive manufacturing. This paper presents a decision support method for the manufacturing of offshore equipment components, and compares a standard subtractive method with an additive manufacturing approach. An analytic hierarchy process was applied to select the most effective and efficient production method, considering CNC milling and direct metal laser sintering. A final set of decision criteria that take into account the specifics of the offshore industry sector are provided.
\end{abstract}

Keywords: offshore industry, additive technologies, maritime and offshore equipment components, decision support systems, analytic hierarchy process (AHP)

\section{INTRODUCTION}

Additive technologies, commonly referred to as $3 \mathrm{D}$ printing, are a set of methods enabling the layered construction of objects based on 3D computer models, and without using part-dependent tools $[1,15]$. The strong increase in interest in additive technologies that has been particularly noticeable in recent years is related to developments in the methods and systems of 3D printing [33]. Advanced materials, including those with reinforcement phases, can be used to create products $[26,29,32]$. The current range of components that can be made by additive technologies extends beyond the original applications of rapid prototyping. In particular, 3D printing with metal powder allows for the production of fully functional spare parts for mechanical devices. The term additive manufacturing (AM) refers to the fabrication of components with specific mechanical and functional properties.

Nowadays, high-quality, reliable components for offshore industry are manufactured by material removal processes, including five-axis milling. Additive technologies are characterised by their competitive features compared to traditional machining methods. The main advantages of AM include the design and manufacture of components with complex geometry. The manufacture of these types of objects can be difficult and sometimes impossible to achieve with the use of traditional cutting and casting methods. Other advantages are the relatively short processing time and the lack of a need for production tools. These factors may also reduce the overall production costs.

The wide variety of manufacturing techniques that are currently available, such as material removal processes and $3 \mathrm{D}$ printing powder technology, must be taken into account during the selection of the most efficient fabrication method. This must involve consideration of the relevant criteria related to the capabilities of the specific manufacturing techniques. This paper presents the results obtained from a multi-criteria decision making (MCDM) method called an analytic hierarchy process (AHP) for the selection of the 
(a)

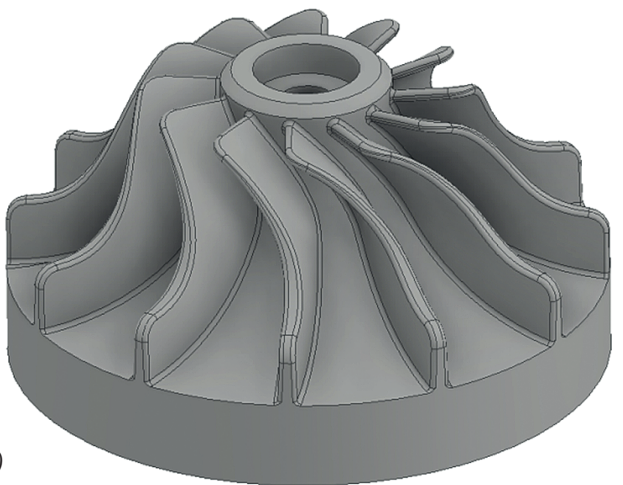

(b)

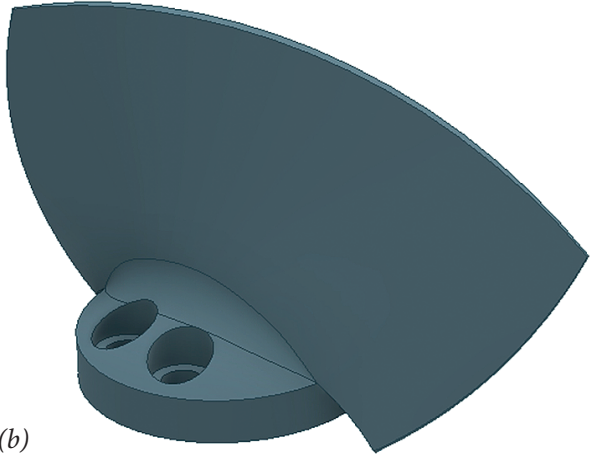

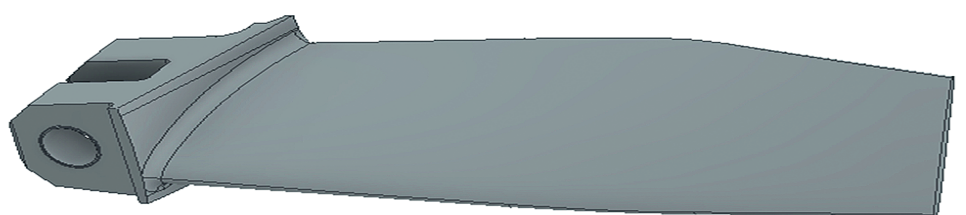

(c)

Fig. 1. Examples of mechanical components with free-form surfaces that can be produced be additive manufacturing

(a) impeller; (b) short propeller blade; (c) long propeller blade

most suitable technology for manufacturing components for offshore machinery, using the example of an impeller. The type and form of the material, its mechanical and physical properties, and the production time and cost were analysed and compared in the process of selecting the most suitable fabrication method using a multi-criteria analysis.

\section{ADDITIVE MANUFACTURING IN OFFSHORE INDUSTRY}

The maritime industry is one of the leading areas for the potential application of additive technologies. The mechanical components of marine constructions are affected by environmental factors such as sea water and variability in the loads that affect these structures. Demanding and difficult working conditions cause frequent damage to the components of technical equipment used in the coastal zone and at sea. The efficiency of machines can therefore be maintained and process continuity improved through the rapid manufacture of spare parts. $3 \mathrm{D}$ printing technologies can offer an alternative to the traditional material removal processes generally used in the offshore industry. Nowadays, the most common and advanced additive technologies include direct metal laser sintering (DMLS) and electron beam melting (EBM). These allow for the production of elements with complex geometries (Fig. 1) consistently highlevel mechanical properties, and homogeneous internal structures. The process of $3 \mathrm{D}$ printing is based on the direct conversion of $3 \mathrm{D}$ data into physical objects by applying successive layers of material in the form of powder, which can be either melted or sintered. Among the benefits of this technology is that it allows for flexible production of various items at no extra cost in terms of manufacturing, without the need for additional tools or moulds [19]. Table 1 presents the characteristics of the $3 \mathrm{D}$ metal powder technologies currently used in this industry.

$3 \mathrm{D}$ printing powder technologies can be used to produce a wide range of complex machine elements for different sectors of industry with similar characteristics, including the maritime and shipping industry. According to [19], this industry can be characterised as conservative with respect to change, although DMLS and selective laser melting (SLM) technologies are currently being successfully used to manufacture high-pressure blades for gas and Tesla turbines $[7,14,18,20,23,30]$. These kinds of parts have complex geometries, including inner features in the form of miniature holes [10] and channels for delivering cooling

Tab. 1. Characteristics of $3 D$ metal powder technologies currently used in different sectors of industry

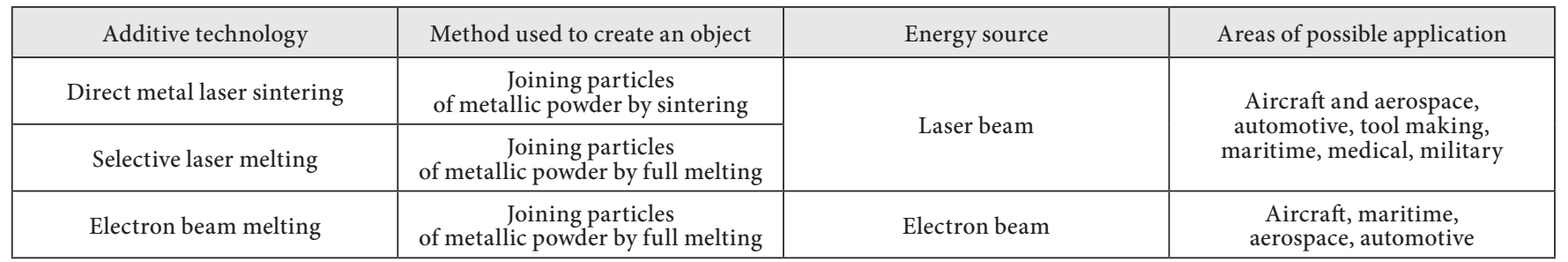


Tab. 2. Scale of relative importance, adapted from Saaty [25]

\begin{tabular}{|c|c|c|}
\hline Intensity of importance & Description & Explanation \\
\hline 1 & Equally important & Two factors contribute equally to the objective \\
\hline 3 & Slightly more important & Experience and judgement slightly favour one factor over the other \\
\hline 5 & Much more important & Experience and judgement strongly favour one factor over the other \\
\hline 7 & Significantly important & $\begin{array}{l}\text { Experience and judgement very strongly favour one factor over the other to show } \\
\text { its dominance in practice }\end{array}$ \\
\hline 9 & Extremely important & The evidence favouring one factor over the other is of the highest possible validity \\
\hline $2,4,6,8$ & Intermediate values & Always used where a compromise is required \\
\hline Reciprocals of the above & \multicolumn{2}{|c|}{$\begin{array}{l}\text { If a criterion } i \text { has one of the above non-zero members assigned to it when compared with criterion } j \text {, then } j \\
\text { has the reciprocal value when compared with } i\end{array}$} \\
\hline
\end{tabular}

fluid. The creation of complex inner features by conventional machining methods can be difficult, and in some cases even impossible. Industrial impellers are another group of parts commonly used in the marine industry, and these can be made by 3D powder technologies [28]. In addition to their complex geometries, elements of this type have thin walls, which are difficult to make by material removal processes.

Hybrid manufacturing is a promising approach for widening the scope of AM applications. DMLS can be used in association with more traditional processes, such as electrodischarge machining (EDM) or high-speed machining (HSM) to give a hybrid rapid tooling process [22] that can reduce the time needed to create tools and dies.

The use of AM can therefore be a beneficial solution for the rapid production of spare parts on ships and major systems on platforms or offshore industrial installations, which operate in remote locations and are in continuous movement. Spare parts must often be delivered in a timely manner to the next port of call of the ship. AM can shorten the supply chain for spare parts in the maritime industry, since the part can be made near to or even in the place where it will be needed [19]. Although AM can be used to create a wide variety of products in a controlled and static environment, the use of such techniques while afloat creates questions about the feasibility of the incremental processes [27].

AM technology can radically change supply chains, product designs and production in several sectors of industry, thanks to advantages such as on-demand, localised production and the ease of creating complex shapes. However, cost-effectiveness considerations, gaps in knowledge, process variability and a lack of full standardisation have tended to limit the adaptation of AM within the maritime construction sector [2]. The standardisation and normalisation of AM processes currently under way will certainly help in identifying and widening the possibilities for implementation in offshore industry $[11,21]$.

The selection of an appropriate manufacturing method is one of the most crucial decisions in the product development cycle $[8,9]$. We therefore propose a decision support method for manufacturing offshore equipment components. AHP is applied to the selection of the most effective and efficient production method, including CNC milling and DMLS, and a set of decision criteria that take into account the specifics of the offshore industry sector are developed. The resultant ranking list of analysed alternatives is generated.

\section{MULTI-CRITERIA DECISION MAKING USING THE AHP METHOD}

MCDM is one of the most well-known approaches to making decisions in the presence of multiple, often opposing objectives. Characteristic features considered in MCDM include alternatives, attributes, criteria and sub-criteria, weights representing their importance, and decision matrices. The AHP method, introduced by Saaty [25], is one of the most commonly applied methods in this area. It enables the determination of the priorities of a set of alternatives and the relative importance of individual factors in a multicriteria evaluation task $[24,31]$. In this approach, relatively simple pairwise comparison judgements are carried out, which are then utilised to develop overall priorities that are used to rank the alternatives. The quantification of priorities is typically carried out using integers in the range one to nine and their reciprocals (Table 2) [6,25].AHP involves applying consecutive steps in the frame of an iterative procedure, as listed below:

Step 1. Definition of the problem and decomposition into a systematic hierarchical structure, including the definition of the main criteria/sub-criteria used with a comparative analysis of process alternatives.

Step 2. Creation of matrices for pairwise comparisons of the selected main criteria, using an established rating scale as shown in Table 2.

Step 3. Calculation of the importance weights for individual criteria and determination of an appropriate ranking list to identify preferences for the criteria based on which alternatives are evaluated. This activity is equivalent to computing the vectors of normalised weights for criteria or sub-criteria. This step is followed by validation of the previous calculations.

Step 4. Checks on the consistency of the relevant matrix formed at specified levels of the hierarchy, corresponding to definite sets of criteria or sub-criteria. This validation-related activity entails calculations of the principal eigenvalues of 


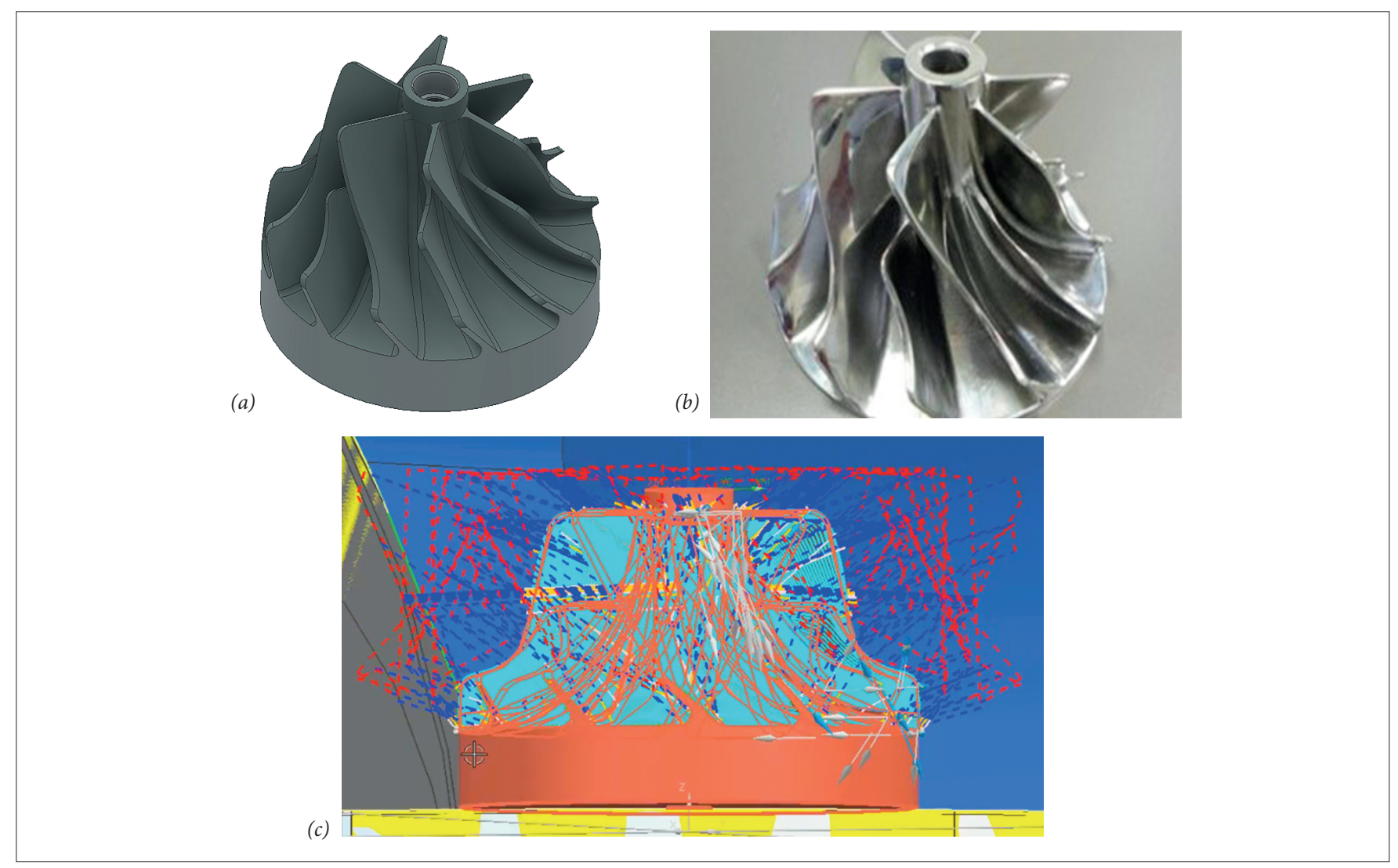

Fig. 2. Example of a part used in an illustrative case study: (a) 3D model of an impeller type part; (b) real part; (c) tool paths used in the estimation of machining time

the relevant matrices, and the values of the consistency index $(C I)$ and consistency ratio $(C R)$. Consistency of the matrices generated in the decision process requires that, in any instance, inequality constraints (1) and (2) are met:

$$
\begin{gathered}
C I=\frac{\lambda_{\max }-n}{n-1} \leq 0,1 \\
C R=\frac{C I}{R I} \leq 0,1
\end{gathered}
$$

where: $\lambda_{\max }$ is the maximum eigenvalue of the relevant matrix, $n$ is the order of the matrix, and $R I$ is a random index that depends on the value of $n$ [20].

It should be noted that the value of $\lambda_{\max }$ can be computed as a sum of the products of each weight of the criteria (alternatives) and the calculated sums of columns derived from the matrix of pairwise comparisons of criteria (alternatives).

In the decision scheme, the calculations carried out in steps 2-4 need to be repeated with respect to the lower level of the hierarchy, i.e. with regard to all related subordinate criteria. Consequently, the preferences for the sub-criteria are computed both locally and globally. The local weights (reflecting the importance) of both criteria and sub-criteria are determined as arithmetic averages. The global importance (weight) of each subordinate criterion is in turn computed as the product of its relative (local) weight and the weight(s) of the criterion at the respective level(s) of the hierarchy.

Step 5. Creation of matrices for pairwise comparisons of the process alternatives in terms of individual decision criteria, using the established rating scale given in Table 2. This procedure is continued after checking of the validation conditions given in Step 4.

Step 6. Computation of the matrix $S=\left[S_{i j}\right]_{m \times n}$ of normalised performance metrics (scores) for the alternatives for each criterion, where $i=1, \ldots, m$, and $m$ is the total number of alternatives, and where $j=1, \ldots, n$, and $n$ is the total number of assumed criteria (design/process attributes).

As a result, a list of preferences of the alternatives being compared (i.e. a ranked list of alternatives) is produced on a global scale, based on the sum of the partial values of the normalised performance metrics calculated with reference to individual criteria, as recorded in the $S$ matrix.

\section{METHODS OF MANUFACTURING AN IMPELLER COMPONENT}

Impellers and turbine blades are widely used in equipment for the maritime industry. These types of parts are characterised by a complex geometry with thin walls. The selection of the most efficient manufacturing method requires consideration of numerous factors related to the material, mechanical and functional properties of the product, as well as the speed and cost of delivering the final components. CNC machining with a five-axis milling machine was used to manufacture an impeller component (Fig. 2). The DMLS method, as the most suitable $3 \mathrm{D}$ printing technology, was also used. 
Tab. 3. Parameters of the methods for manufacturing an impeller

\begin{tabular}{|c|c|c|c|}
\hline \multirow{2}{*}{ Parameter } & \multicolumn{3}{|c|}{ Manufacturing method } \\
\hline & CNC milling & \multicolumn{2}{|c|}{ DMLS } \\
\hline Machine & Pinnacle AX $320^{*}$ & \multicolumn{2}{|c|}{ EOSINT M280** } \\
\hline Material & Steel 34 HNM/1.6582 (34CrNiMo6) & $\begin{array}{c}\text { EOS } \\
\text { nickel alloy IN718 }\end{array}$ & EOS maraging steel MS1 \\
\hline Material form & Rod bar & \multicolumn{2}{|c|}{ Powder; thickness of a single layer of material: $40 \mu \mathrm{m}$} \\
\hline \multicolumn{4}{|c|}{$\begin{array}{l}\text { Note: } \\
\text { * The Pinnacle AX320 with Heidenhain TNC640 is a five-axis milling machine tool. The applied material (steel } 34 \mathrm{HNM} \text { ) is used to build highly loaded } \\
\text { parts, exposed to impacts, twisting, and vibrations like turbine blades and impellers. } \\
\text { ** EOSINT M280 3D printer is a market-leading industrial system working in DMLS/SLM technology. EOS Nickel Alloy IN718 is characterised by high } \\
\text { strength, resistance to high temperatures and very high corrosion resistance. EOS MaragingSteel MS1 is also characterised by high strength and } \\
\text { hardness, and is therefore commonly used to build elements for injection moulds. }\end{array}$} \\
\hline
\end{tabular}

Tab. 4. A set of decision criteria for selecting the method of manufacturing an impeller

\begin{tabular}{|c|c|c|c|}
\hline \multirow{2}{*}{ Criteria } & \multicolumn{3}{|c|}{ Manufacturing method } \\
\hline & CNC-milling & DMLS IN718 & DMLS MS1 \\
\hline \multicolumn{4}{|c|}{ Mechanical and physical properties } \\
\hline Tensile strength (MPa) & 1400 & $\begin{array}{l}1060-\mathrm{x}, \mathrm{y} \text { direction } \\
1400-\mathrm{z} \text { direction }\end{array}$ & $\begin{array}{l}2050-x, y \text { direction } \\
2050-z \text { direction }\end{array}$ \\
\hline Material density (g/cm3) & 8 & 8.15 & $8.0-8.1$ \\
\hline Hardness (HRC) & 60 & 47 & $50-56$ \\
\hline \multicolumn{4}{|c|}{ Process-related factors } \\
\hline Processing time $[\mathrm{min}]^{\star}$ & 596 & 2520 & 2520 \\
\hline Roughness $[\mu \mathrm{m}]$ & $\mathrm{Ra}=0.4-0.6$ & $\mathrm{Ra}=2.5-3.5$ & $\mathrm{Ra}=2.5-3.5$ \\
\hline Accuracy of manufacture $[\mathrm{mm}]$ & $+/-0.02$ & $+/-0.05$ & $+/-0.05$ \\
\hline \multicolumn{4}{|c|}{ Costs of manufacturing } \\
\hline Material cost $[€]$ & 60 & 270 & 257 \\
\hline Total processing cost $[€]$ & 955 & 1540 & 1540 \\
\hline Post-processing cost $[€]$ & 0 & 80 & 80 \\
\hline $\begin{array}{l}\text { Note: } \\
\star \text { |Includes the machining and set } \\
\text { the support structure with a heig } \\
\text { powder technology, the time cor }\end{array}$ & $\begin{array}{l}\text { egard to DM } \\
\text { d the setup ti } \\
\text { es heating of }\end{array}$ & $\begin{array}{l}\text { chining time is rel } \\
\text { paration of the ma } \\
\text { nd cooling down }\end{array}$ & $\begin{array}{l}\text { g of the impeller m } \\
\text { g. In the case of } 3 \mathrm{D} \\
\text { uring process. }\end{array}$ \\
\hline
\end{tabular}

Important parameters related to these manufacturing processes, such as the machine, type and the form of the material, are listed in Table 3.

In order to solve a decision problem concerning the selection of the most efficient method for manufacturing an impeller, three main criteria and nine sub-criteria were defined (Table 4). These sets of main and sub-criteria were determined in view of the possible heavy-duty operating conditions of the impeller in a maritime equipment.

The anisotropic mechanical properties of the 3D metal printed components shown in Table 4, are examples of the basic disadvantages of additive technology, and may affect the functionality of an impeller working under variable loading conditions. In view of this, a strength analysis must be carried out at the design stage that takes into account the mechanical properties arising from the orientation of the component in the working chamber of the $3 \mathrm{D}$ printer. It was assumed in this study that selected materials meet established design requirements, in accordance with material data sheets $[12,13]$.
Data on the mechanical and physical properties and the accuracy of manufacture were determined considering the heat treatment in additive $[12,13]$ and subtractive processes $[34,35]$.

Output process parameters concerning the times required for printing (2220 minutes) and related setup (300 minutes) were calculated using dedicated EOSINT M280 software. The machining time for the subtractive method was derived using a CNC Heidenhain TNC640 controller and amounted to 553 minutes, and the setup time was 43 minutes.

The $3 \mathrm{D}$ printing of the impeller involves the cost of the utilised material, depending on the model volume. The operating costs of the 3D printer were also included, following manufacturing practices recommended by the Institute of Fundamental Technological Research, Polish Academy of Sciences. The cost of using the 3D printer was assumed to be $70 €$ per hour, taking into account factors such as the cost of acquisition and installation, a five-year amortisation period (i.e. $20 \%$ per year), maintenance costs, and the costs of energy and ancillary materials. In the case of DMLS technology, the required post-processing costs, such as cleaning the model of 

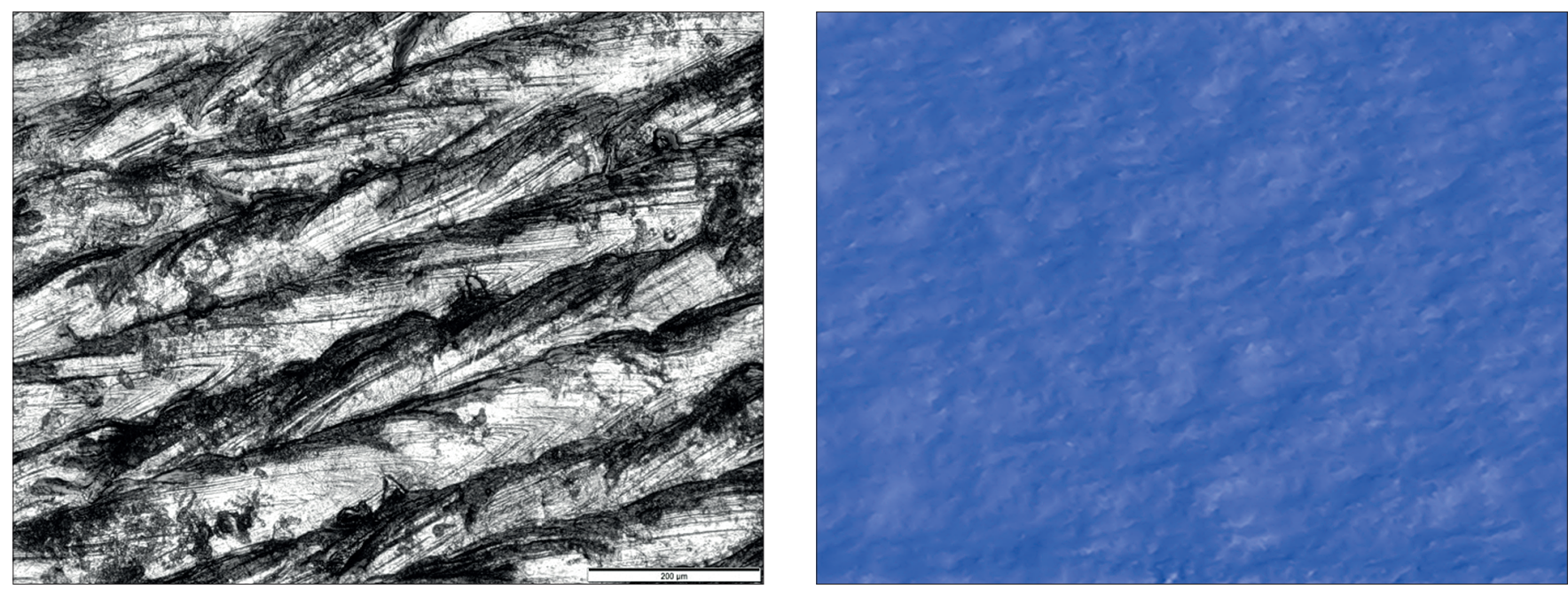

Fig. 3. Part of the surface of a workpiece made of MS1 material by DMLS: (a) a microscopic image of a real surface using OLYMPUS BX51;

(b) digital model of the surface obtained with computer tomography

the remaining unmelted powder, shot-peening and additional heat treatment, were also taken into account.

The total operation cost of CNC milling, $\mathrm{C}_{\mathrm{o}}$, comprised two components: machine costs and tool utilisation costs. It was calculated using the following cost model for a multi-cut operation [3]:

$$
C_{o}=c_{o i} \sum_{\frac{t_{m i}}{6}+t_{m i i}}^{60}+\sum_{i} c_{T i} \frac{t_{m i}}{T_{i i}}
$$

where $t_{m i}[\mathrm{~min}]$ is the machining time for the tool path of the $i$-th tool, $t_{\text {smi }}[\mathrm{min}]$ is the supplementary machine time for the $i$-th tool, $T_{l i}[\mathrm{~min}]$ is the tool life under cut for the $i$-th tool, $c_{o}$ is the hourly machine operating cost, and $c_{T i}$ [ $€$ tool life under cut of the $i$-th tool] is the cost of the $i$-th tool, calculated as the sum of the costs of amortisation and tool exchange in the magazine.

The costs of using the machine tool during the cutting process were assumed to be $45 €$ per hour, based on the same factors as for the 3D printer. In this case, a seven-year amortisation period was assumed (i.e. $14.3 \%$ per year), due to the relatively slow technological development of CNC machine tools compared to 3D printing equipment.

Nineteen tools of various types were utilised in the milling of the impeller, including an end mill, a spherical mill, chamfer mill cutters and drillers. In the calculations, the costs of the individual tools were assumed to be in the range $27-36 €$, while the values for the life under cut for the individual tools were between 15 and 30 minutes.

The surface quality (roughness) is another important factor which has a fundamental importance in the functional properties of the impellers, such as their wear and corrosion resistance, strength properties and flow resistance [16]. In industrial practice, to ensure the optimal functioning of parts such as impellers that are subjected to variable loads, a surface roughness in the range $\mathrm{Ra}=0.2-0.6 \mu \mathrm{m}$ is required [17]. This value can be obtained by CNC milling, and has been confirmed by reports in the literature $[4,5]$, as given in Table 4 .
For DMLS, a microscopic analysis was carried out. Fig. 3 shows part of the surface of a workpiece created using this technology.

The images in Figure 3 show that an irregular surface structure, characteristic of DMLS printed elements, was obtained. The results of surface roughness measurements obtained with a Hommel Tester T500 (Fig. 4) were significantly higher than the required surface roughness of $\mathrm{Ra}=0.2-0.6 \mu \mathrm{m}$. To obtain the required surface roughness, which is essential for elements such as impellers, there is therefore a need to perform additional finishing operations to smooth the surface. In the calculations below, the values of achievable Ra parameter were assumed based on the results of the authors' research and literature reports (Table 4).

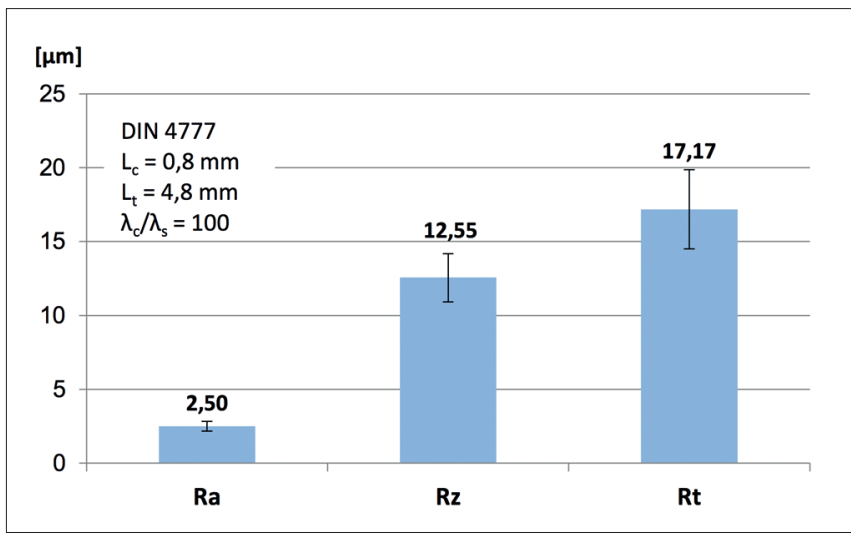

Fig. 4. Parameters of the surface roughness of a workpiece made of MS1 by DMLS

\section{AHP-BASED SELECTION OF IMPELLER MANUFACTURING TECHNOLOGY}

The application of the AHP method as an efficient decision support framework, has been demonstrated as a case study of manufacturing impeller-type components. The first step in the process of selecting a manufacturing technology for an impeller using AHP is to develop a hierarchical structure for 


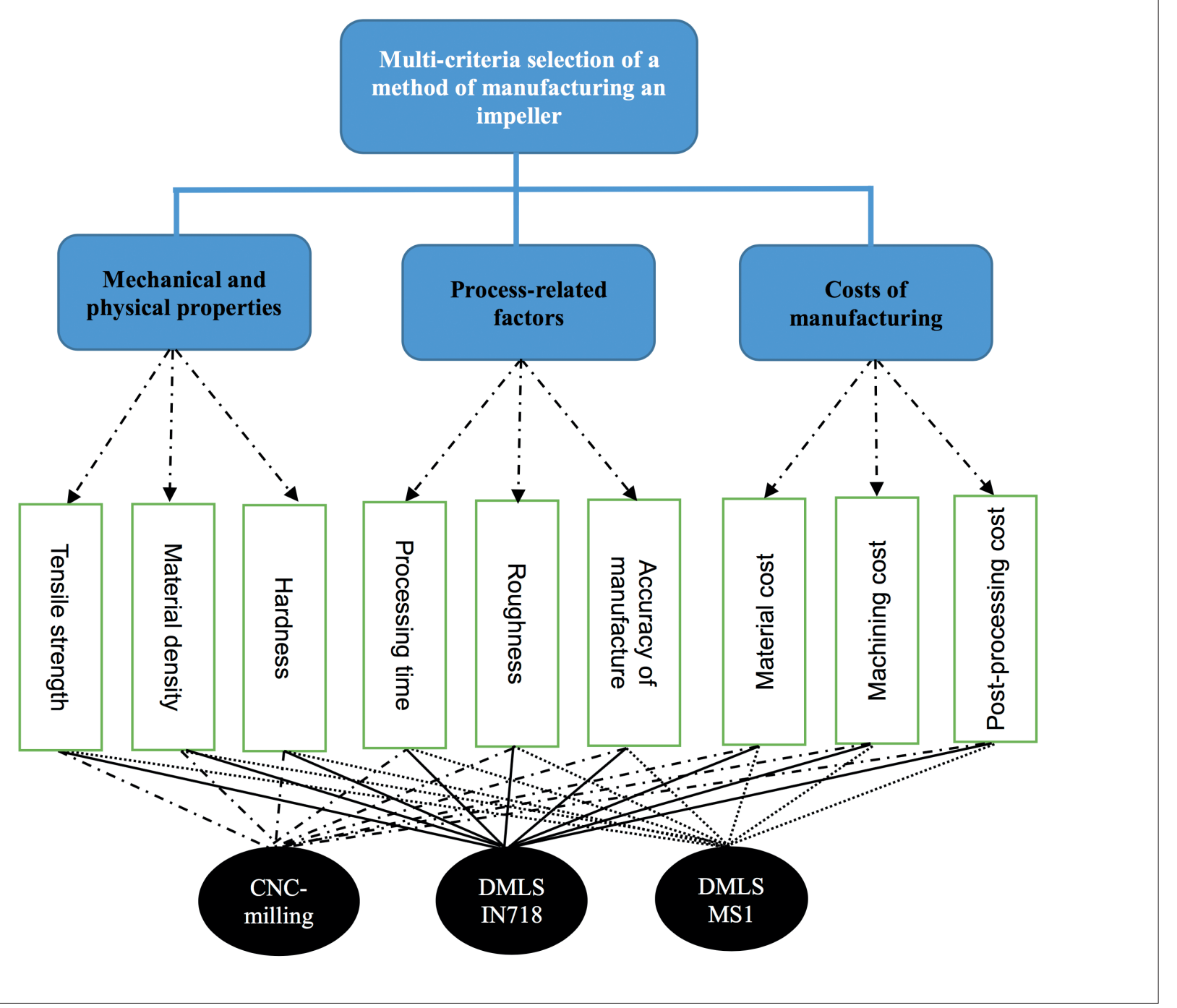

Fig. 5. Hierarchical structure of the decision problem related to selecting the impeller manufacturing technology with the AHP method

the decision problem (see Step 1 above). In the present study, the hierarchical diagram consists of four levels: the goal of the decision problem, the main criteria level, the sub-criteria level, and the scheme level, which is related to the overall rankings and the selection of the best process alternatives (Fig. 4).

At the next level, the main criteria were quantitatively assessed using pairwise comparisons. The results of these calculations are shown in Tables 5 and 6.

Tab. 5. Pairwise comparisons of the main criteria

\begin{tabular}{|c|c|c|c|c|}
\cline { 2 - 5 } \multicolumn{1}{c|}{} & $\begin{array}{c}\text { Mechanical } \\
\text { and physical } \\
\text { properties }\end{array}$ & $\begin{array}{c}\text { Process } \\
\text { related } \\
\text { factors }\end{array}$ & $\begin{array}{c}\text { Costs of } \\
\text { manufa- } \\
\text { cturing }\end{array}$ & Sum \\
\hline $\begin{array}{c}\text { Mechanical and } \\
\text { physical properties }\end{array}$ & 1 & 4 & 6 & 11 \\
\hline $\begin{array}{c}\text { Process-related } \\
\text { factors }\end{array}$ & 0.25 & 1 & 3 & 4.25 \\
\hline $\begin{array}{c}\text { Costs of } \\
\text { manufacturing }\end{array}$ & 0.17 & 0.33 & 1 & 1.50 \\
\hline Sum & 1.42 & 5.33 & 10 & \multicolumn{1}{|c}{} \\
\cline { 1 - 5 } & & \multicolumn{2}{|c|}{}
\end{tabular}

Pairwise comparisons of the main criteria were used to compute the importance weights of the individual main criteria (Steps 2 and 3 above), and based on these weights, a ranking list of the main criteria was created. Following the AHP methodology, the principal eigenvalue of $\lambda_{\max }$ was calculated and the validation conditions were checked using the consistency index (CI) and consistency ratio (CR).

\begin{tabular}{|c|c|c|c|c|c|}
\multicolumn{1}{c|}{ Tab. 6. Importance of the main criteria } & Rank \\
\cline { 2 - 6 } & $\begin{array}{c}\text { Mechanical } \\
\text { and } \\
\text { physical } \\
\text { properties }\end{array}$ & $\begin{array}{c}\text { Process } \\
\text { related } \\
\text { factors }\end{array}$ & $\begin{array}{c}\text { Costs of } \\
\text { manufa- } \\
\text { cturing }\end{array}$ & Weight & Ren \\
\hline $\begin{array}{c}\text { Mechanical } \\
\text { and physical } \\
\text { properties }\end{array}$ & 0.71 & 0.75 & 0.60 & 0.685 & 1 \\
\hline $\begin{array}{c}\text { Process-related } \\
\text { factors }\end{array}$ & 0.18 & 0.19 & 0.30 & 0.221 & 2 \\
\hline $\begin{array}{c}\text { Costs of } \\
\text { manufacturing }\end{array}$ & 0.12 & 0.06 & 0.10 & 0.093 & 3 \\
\hline Sum & 1 & 1 & 1 & & \\
\hline
\end{tabular}


The values at this level of the analysis are as follows (for $\left.\lambda_{\max }=3.085\right)$ :

$$
\begin{gathered}
C I=\frac{3.085-3}{3-1}=0.043 \leq 0.1, \\
\text { and } \\
C R=\frac{0.043}{0.52}=0.082 \leq 0.1 .
\end{gathered}
$$

The relevant calculations at the level of the subordinate criteria (Step 4) were performed in the same way as for the main criteria. All of the weight values at this level (i.e. at the global scale) were obtained by multiplying the local weights by the weight of the corresponding criteria. The results for the sub-criteria for the mechanical and physical properties of impeller material are given in Tables 7 and 8, respectively.

Tab. 7. Pairwise comparisons of the sub-criteria for the mechanical and physical properties of the impeller material

\begin{tabular}{|c|c|c|c|c|}
\cline { 2 - 5 } \multicolumn{1}{c|}{} & $\begin{array}{c}\text { Tensile } \\
\text { strength }\end{array}$ & $\begin{array}{c}\text { Material } \\
\text { density }\end{array}$ & Hardness & Sum \\
\hline $\begin{array}{c}\text { Tensile } \\
\text { strength }\end{array}$ & 1 & 4 & 5 & 10 \\
\hline $\begin{array}{c}\text { Material } \\
\text { density }\end{array}$ & 0.25 & 1 & 3 & 4.25 \\
\hline Hardness & 0.17 & 0.33 & 1 & 1.50 \\
\hline Sum & 1.42 & 5.33 & 9 & \multicolumn{1}{|c|}{} \\
\cline { 1 - 5 }
\end{tabular}

Tab. 8. Importance of the sub-criteria for the mechanical and physical properties of the impeller material

\begin{tabular}{|c|c|c|c|c|c|c|}
\cline { 2 - 6 } \multicolumn{1}{c|}{} & $\begin{array}{c}\text { Tensile } \\
\text { strength }\end{array}$ & $\begin{array}{c}\text { Material } \\
\text { density }\end{array}$ & $\begin{array}{c}\text { Hard- } \\
\text { ness }\end{array}$ & $\begin{array}{c}\text { Local } \\
\text { weight }\end{array}$ & $\begin{array}{c}\text { Global } \\
\text { weight }\end{array}$ & Ranking \\
\hline $\begin{array}{c}\text { Tensile } \\
\text { strength }\end{array}$ & 0.71 & 0.75 & 0.56 & 0.670 & 0,459 & 1 \\
\hline $\begin{array}{c}\text { Material } \\
\text { density }\end{array}$ & 0.18 & 0.19 & 0.33 & 0.232 & 0,159 & 2 \\
\hline Hardness & 0.12 & 0.06 & 0.11 & 0.097 & 0,067 & 3 \\
\hline Sum & 1 & 1 & 1 & 1 & 0,69 & \multicolumn{1}{c|}{} \\
\cline { 1 - 6 } & & &
\end{tabular}

The results of the consistency test at this level showed that the required conditions (see Eqs. 1 and 2) were met. The values obtained for $C I$ and $C R$ coefficients are given below for $\lambda_{\max }=3.063$ :

$$
\begin{gathered}
C I=\frac{3.063-3}{3-1}=0.032 \leq 0.1, \\
\text { and } \\
C R=\frac{0.032}{0.52}=0.061 \leq 0.1, .
\end{gathered}
$$

Tables 9 and 10 present comparisons of the results for the alternative processes (Steps 5 and 6 above) from the viewpoint of the tensile strength, which turned out to be the most important factor in the mechanical and physical properties of the material. These results were obtained in a similar way to the corresponding calculations at the subcriteria level.
Tab. 9. Pairwise comparison of the alternatives in terms of the criterion tensile strength for applied material

\begin{tabular}{|c|c|c|c|c|}
\cline { 2 - 4 } \multicolumn{1}{c|}{} & $\begin{array}{c}\text { CNC } \\
\text { milling }\end{array}$ & $\begin{array}{c}\text { DMLS- } \\
\text { IN718 }\end{array}$ & $\begin{array}{c}\text { DMLS- } \\
\text { MS1 }\end{array}$ & \multirow{2}{*}{ Sum } \\
\hline $\begin{array}{c}\text { Tensile } \\
\text { strength }\end{array}$ & 1400 & 1060 & 2050 & \\
\hline CNC milling & 1 & 2 & 0.25 & 3.25 \\
\hline DMLS-IN718 & 0.50 & 1 & 0.20 & 1.70 \\
\hline DMLS-MS1 & 4 & 5 & 1 & 10 \\
\hline Sum & 1.63 & 3.13 & 18 & \\
\hline
\end{tabular}

Tab. 10. The importance of the tensile strength sub-criterion

\begin{tabular}{|c|c|c|c|c|c|c|}
\cline { 2 - 7 } \multicolumn{1}{c|}{} & $\begin{array}{c}\text { CNC } \\
\text { milling }\end{array}$ & $\begin{array}{c}\text { DMLS- } \\
\text { IN718 }\end{array}$ & $\begin{array}{c}\text { DMLS- } \\
\text { MS1 }\end{array}$ & $\begin{array}{c}\text { Local } \\
\text { weight }\end{array}$ & $\begin{array}{c}\text { Global } \\
\text { weight }\end{array}$ & Ranking \\
\hline $\begin{array}{c}\text { CNC } \\
\text { milling }\end{array}$ & 0.18 & 0.25 & 0.17 & 0.201 & 0.063 & 2 \\
\hline $\begin{array}{c}\text { DMLS- } \\
\text { IN718 }\end{array}$ & 0.09 & 0.13 & 0.14 & 0.118 & 0.037 & 3 \\
\hline $\begin{array}{c}\text { DMLS- } \\
\text { MS1 }\end{array}$ & 0.73 & 0.63 & 0.69 & 0.681 & 0.214 & 1 \\
\hline Sum & 1 & 1 & 1 & 1 & 0.31 & \multicolumn{2}{c}{} \\
\cline { 1 - 7 } & & & & & &
\end{tabular}

The validation conditions were also checked (Step 4) and were shown to be fulfilled, as shown below, for an eigenvalue of $\lambda_{\max }=3.038$ :

$$
\begin{gathered}
C I=\frac{3.038-3}{3-1}=0.019 \leq 0.1, \\
\text { and } \\
C R=\frac{0.019}{0.52}=0.037 \leq 0.1, .
\end{gathered}
$$

Finally, the partial values of the normalised performance metrics, calculated for each of the process alternatives and for all nine decision criteria, are shown in Table 11. This table also includes the cumulative values of the performance metrics for each alternative, and its ranking. Cutting technology, with a value of 0.744 , was the best alternative. It can be observed that for $\mathrm{CNC}$ machining, factors related to the manufacturing process accounted for around $84 \%$ of the cumulative value of the normalised performance. The accuracy of manufacture is the largest component, amounting to around $81 \%$. These criteria also have high levels of importance for DMLS technology, and in particular for Nickel Alloy IN718 yield altogether $79 \%$ for process related factors, but with the lowest cumulative value (0.259). For Maraging Steel MS1, however, the mechanical and physical properties have the largest impact on the cumulative value of normalised performance, at around $54 \%$. The results of a quantitative evaluation of the alternatives, based on the above calculations, are also presented in the form of a bar chart (Fig. 6). CNC milling proved to be the most appropriate method for fabricating this type of offshore machinery component, and is used in current industrial practice. However, in the near future, following the intensive development of additive technologies, 3D printing may gain an advantage over subtractive technologies. 
Tab. 11. Results of the multi-criteria selection of alternative processes with corresponding ranking

\begin{tabular}{|c|c|c|c|c|c|c|c|c|c|c|c|}
\hline & \multicolumn{3}{|c|}{ Mechanical and physical properties } & \multicolumn{3}{|c|}{ Process related factors } & \multicolumn{3}{|c|}{ Costs of manufacturing } & \multirow[b]{2}{*}{ 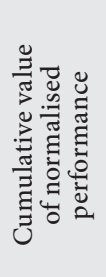 } & \multirow[b]{2}{*}{ 烒 } \\
\hline & 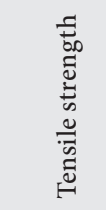 & 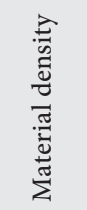 & 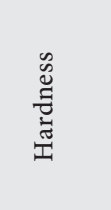 & 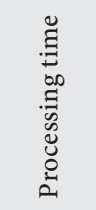 & 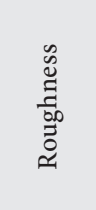 & 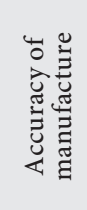 & 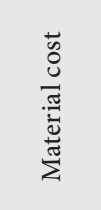 & 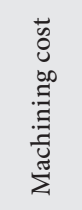 & 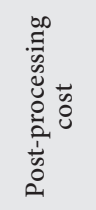 & & \\
\hline $\begin{array}{l}\text { CNC } \\
\text { milling }\end{array}$ & 0.063 & 0.025 & 0.025 & 0.003 & 0.022 & 0.600 & 0.002 & 0.004 & 0.0005 & 0.744 & 1 \\
\hline $\begin{array}{l}\text { DMLS- } \\
\text { IN718 }\end{array}$ & 0.037 & 0.007 & 0.007 & 0.0006 & 0.0045 & 0.200 & 0.0002 & 0.001 & 0.0001 & 0.259 & 3 \\
\hline $\begin{array}{c}\text { DMLS- } \\
\text { MS1 }\end{array}$ & 0.214 & 0.014 & 0.014 & 0.0006 & 0.0045 & 0.200 & 0.0004 & 0.001 & 0.0001 & 0.448 & 2 \\
\hline
\end{tabular}

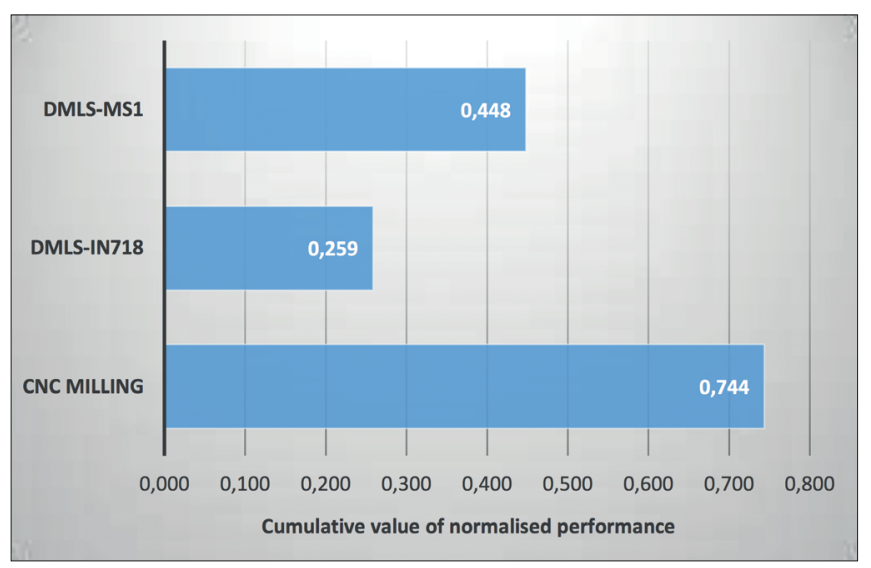

Fig. 6. Comparison of process alternatives based on a multi-criteria evaluation using the AHP method

\section{CONCLUSIONS}

The selection of an appropriate manufacturing method is one of the most crucial decisions in the product development cycle. AM technologies, and especially 3D printing metal powder methods, can radically change supply chains, product designs and production in certain sectors of industry, since a part with complex geometry can be made near or even in the exact place it is needed. However, processing costs and high design requirements might limit the adaptation of AM processes within these industrial sectors. In this study, we propose a decision support method for selecting a suitable manufacturing technology for offshore equipment components, which can help in the wider implementation of DMLS technology in the maritime construction sector.

AHP, as an efficient decision support framework, was applied to the selection of the most suitable manufacturing method for fabrication of complex mechanical components, and an impeller part was used as an illustrative case study. CNC machining and the DMLS method were considered as alternative processes for producing the final part. A final set of decision criteria that focused on the specifics issues of the offshore industry sector were provided, and a ranking list of the analysed alternatives was generated to show that for the specified technical requirements and production resources,
CNC milling was the highest-ranked position. Taking into account the intensive developments in DMLS technology, including the dynamic development of contemporary engineering materials, it can be expected that the importance of the main criteria will change. In consequence, the ranking positions of process alternatives may differ from those presented here.

Further research work will focus on the continuous development of the DMLS process and the standardisation measures that are periodically introduced in the offshore sector for critical components in maritime constructions. In particular, the use of DMLS systems while afloat should be also examined before making the decision to build products or spare parts that are normally produced in a controlled, static environment.

\section{ACKNOWLEDGEMENTS}

The authors would like to thank Dr. Piotr Pawłowski from the Department of Intelligent Technologies, Institute of Fundamental Technological Research Polish Academy of Sciences (https://www.ippt.pan.pl/) and Mr. Piotr Sender from RADMOR S.A. (http://www.radmor.com.pl/eng) for providing the data used in this research.

Computations were carried out using software and computers from Academic Computer Centre in Gdansk TASK (http://www.task.gda.pl).

\section{REFERENCES}

1. ASTM, ISO. ASTM52900-15 (2015): Standard Terminology for Additive Manufacturing_General Principles-Terminology, ASTM International, West Conshohocken, PA.

2. Bergsma J.M., Van der Zalm M., Pruyn J.F.J. (2016): 3D-Printing and the Maritime Construction Sector. In: 10th Symposium on High-Performance Marine Vehicles, HIPER 16, Cortona, 17-19 oktober 2016; Part of collection Maritime Archive, p. 428-442. 
3. Bocheński T., Deja M., Siemiątkowski M.S. (2016): Planning Strategies for Complex Shape Pocket Milling in Mechanical Parts (in Polish). Mechanik, 89(10), 1496-1497.

4. Burek J., Żurek P., Żurawski K. (2016): The Influence of Inclination Angle on Surface Roughness with Milling Using a Ball Mill (in Polish). Mechanik, 10, 1478-1479.

5. Chen X., Zhao J., Dong Y., Han S., Li A., Wang D. (2013): Effects of Inclination Angles on Geometrical Features of Machined Surface in Five-Axis Milling. Intl. Journal of Advanced Manufacturing Technology, 65, 1721-1733.

6. Çimren E., Çatay B., Budak E. (2007): Development of a Machine Tool Selection System Using AHP. The International Journal of Advanced Manufacturing Technology, 35(3-4), 363-376.

7. Deja M., Dobrzyński M., Flaszyński P., Haras J., Zieliński D. (2018): Application of Rapid Prototyping Technology in the Manufacturing of Turbine Blade with Small Diameter Holes. Polish Maritime Research, 25(s1), 119-123.

8. Deja M., Siemiątkowski M.S. (2018): Machining Process Sequencing and Machine Assignment in Generative FeatureBased CAPP for Mill-Turn Parts. Journal of Manufacturing Systems, 48, 49-62.

9. Deja M., Siemiątkowski M.S., Sender P. (2017): Comparative Study of Machining Technology Selection to Manufacture Large-Size Components of Offshore Constructions. Polish Maritime Research, 24(s1), 38-45.

10. Deja M., Zieliński D. (2020): A Pilot Study to Assess an In-Process Inspection Method for Small Diameter Holes Produced by Direct Metal Laser Sintering. Rapid Prototyping Journal, 26(2), 418-436.

11. DNVGL-CG-0197, Class Guideline, Additive Manufacturing - Qualification and Certification Process for Materials and Components, available at: http://www.dnvgl.com (accessed 28 March 2019).

12. EOS GmbH - Electro Optical Systems, EOS NickelAlloy IN718, available at: https://drukarki3d.pl/wp-content/ uploads/2015/09/karta-materia\% C5\%82owa-EOSNickelAlloy-IN718-ENG.pdf (accessed 9 April 2019).

13. EOS GmbH - Electro Optical Systems, EOS MaragingSteel MS1, available at: https://drukarki3d.pl/wp-content/ uploads/2015/09/karta-materia\%C5\%82owa-EOSMaragingSteel-MS1-ENG.pdf (accessed 10 May 2019).

14. Flaszynski P., Doerffer P., Piotrowicz M. (2017): Effect of Jet Vortex Generators on Shock Wave Induced Separation on Gas Turbine Profile. In: Proceedings of the 13th
International Symposium on Experimental Computational Aerothermodynamics of Internal Flows, 7-11 May 2017, Okinawa, Japan.

15. Gebhardt A. (2011): Understanding Additive Manufacturing. Carl Hanser Verlag, Munich 2012, p. 2.

16. Grzesik W. (2015): Effect of Surface Topography Features of Machine Parts on Machine Service (in Polish). Mechanik, 8(9), 587-593.

17. Grzesik W. (2019): Influence of Surface Roughness on the Fatigue Life of Machine Elements - Experimental Investigations and Simulations (in Polish). Mechanik, 5(6), 307-313.

18. Iftikhar A., Khan M., Alam K., Imran Jaffery S.H., Ali L., Ayaz Y., Khan A. (2013): Turbine Blade Manufacturing Through Rapid Tooling (RT) Process and its Quality Inspection. Materials and Manufacturing Processes, 28(5), 534-538.

19. Kostidi E., Nikitakos N. (2018): Is It Time for the Maritime Industry to Embrace 3D Printed Spare Parts? TransNav: International Journal on Marine Navigation and Safety of Sea Transportation, 12, 3, p. 557-564.

20. Lampart P., Kosowski K., Piwowarski M., Jędrzejewski Ł. (2009): Design Analysis of Tesla Micro-Turbine Operating on a Low-Boiling Medium. Polish Maritime Research, Special issue S1, pp. 28-33.

21. Lloyd's Register Group Limited and TWI Ltd (2017): Guidance Notes for the Certification of Metallic Parts made by Additive Manufacturing. Published by Lloyd's Register Group Limited. Registered office (Reg. no. 08126909), 71 Fenchurch Street, London, EC3M 4BS, United Kingdom, p. 1-9.

22. Mognol P., Rivette M., Jégou L., Lesprier T. (2007): A First Approach to Choose Between HSM, EDM and DMLS Processes in Hybrid Rapid Tooling. Rapid Prototyping Journal, 13(1), 7-16.

23. Navrotsky V., Graichen A., Brodin H. (2015): Industrialisation of 3D Printing (Additive Manufacturing) for Gas Turbine Components Repair and Manufacturing. VGB PowerTech, $12,48-52$.

24. Piotrowski N., Barylski A. (2016): Multi-Criteria Robot Selection Problem for an Automated Single-Sided Lapping System. In Mechatronics: Ideas, Challenges, Solutions and Applications. Springer, Cham, p. 1-13.

25. Saaty, T.L. (1990): Decision Making For Leaders: The Analytic Hierarchy Process for Decisions in a Complex World, RWS Publications, 1990. 
26. Sercombe T.B., Li X. (2016): Selective Laser Melting of Aluminium and Aluminium Metal Matrix Composites. Materials Technology, 31(2), 77-85.

27. Strickland J.D. (2016): Applications of Additive Manufacturing in the Marine Industry. In: Proceedings of PRADS2016, 4th 8th September, 2016 Copenhagen, Denmark, p. 1-5.

28. Tan X., Kok Y., Tor S.B., Chua C.K. (2014): Application of Electron Beam Melting (EBM) in Additive Manufacturing of an Impeller. In: Proceedings of the 1st International Conference on Progress in Additive Manufacturing (Pro-AM 2014), Singapore: Research Publishing Services, p. 327-332.

29. Tekinalp H.L., Kunc V., Valez-Garcia G.M., Duty C.E., Love L.J., Naskar A.K., Blue C.A., Ozcan S. (2014): Highly Oriented Carbon Fiber-Polymer Composites Via Additive Manufacturing. Composites Science and Technology, 105, 144-150.

30. Vaezi M., Safaeian D., Chua C.K. (2011): Gas Turbine Blade Manufacturing by Use of Epoxy Resin Tooling and Silicone Rubber Molding Techniques. Rapid Prototyping Journal, 17(2), 107-115.

31. Velasquez M., Hester P.T. (2013): An Analysis of MultiCriteria Decision Making Methods. International Journal of Operations Research, 10(2), 56-66.

32. Zhao X., Song B., Fan W., Zhang Y., Shi Y. (2016): Selective Laser Melting of Carbon/AlSi10Mg Composites: Microstructure, Mechanical and Electronical Properties. Journal of Alloys and Compounds, 665, 271-281.

33. Zieliński D. (2020): 3D Printing of Polymers on an Industrial Scale in SLS Technology (in Polish). Tworzywa Sztuczne w Przemyśle, 55(1), 71-72.

34. http://akrostal.pl/stale/1-658234crnimo6/?print=pdf (accessed 3 September 2019).

35. https://www.dostal.com.pl/stal-do-ulepszania-cieplnego. html (accessed 3 September 2019).

\section{CONTACT WITH THE AUTHORS}

\author{
Mariusz Deja \\ e-mail:mdeja@pg.edu.pl
}

Gdańsk University of Technology

Faculty of Mechanical Engineering

Department of Manufacturing and Production Engineering

11/12 Gabriela Narutowicza Street, 80-233 Gdańsk

$$
\text { Poland }
$$

Mieczysław Stanisław Siemiątkowski

e-mail:mieczyslaw.siemiatkowski@pg.edu.plGdańsk University of Technology

Faculty of Mechanical Engineering

Department of Manufacturing and Production Engineering 11/12 Gabriela Narutowicza Street, 80-233 Gdańsk

\section{Poland}

\section{Dawid Zieliński}

e-mail:dawid.zielinski@pg.edu.pl Gdańsk University of Technology

11/12 Gabriela Narutowicza Street, 80-233 Gdańsk

\section{Poland}

